\title{
Clinical Aspects and Precipitating Factors of Hepatic Encephalopathy Associated with Cirrhosis in a Cameroonian Population
}

\author{
Mathurin Pierre Kowo 1,2,3* ${ }^{*}$, Edgar Kenne Yimagou1, Firmin Ankouane Andoulo1,4, \\ Antonin Wilson Ndjitoyap Ndam ${ }^{1}$, Bonaventure Jemea ${ }^{1}$, \\ Servais Albert Fiacre Eloumou Bagnaka5 ${ }^{5}$ Patricia Ouamba Guekam³ ${ }^{3}$ Larissa Pessidjo', \\ Eric Tchoumi Leuwat ${ }^{4}$, Dominique Noah Noah ${ }^{5}$, Oudou Njoya ${ }^{1,2,3}$

\footnotetext{
${ }^{1}$ Faculty of Medicine and Biomedical Sciences, The University of Yaoundé I, Yaoundé, Cameroon

${ }^{2}$ Research Laboratory on Viral Hepatitis and Health Communication, Yaoundé, Cameroon

${ }^{3}$ Internal Medicine Unit Yaounde University Teaching Hospital, Yaoundé, Cameroon

${ }^{4}$ Gastroenterology Unit, Central Hospital, Yaoundé, Cameroon

${ }^{5}$ Faculty of Medicine and Pharmaceutical Sciences, The University of Douala, Douala, Cameroon

Email: *kowomathurinp@yahoo.fr, edgarkenneyim@yahoo.fr, ankouaneandoulo@yahoo.com, tonindam3@yahoo.fr, jemea@hotmail.fr, eloumoug@yahoo.fr,patriciaguekam@yahoo.fr, larissapessidjo@gmail.com, tchoumileuwatericpascal@yahoo.com,noahnoahd@yahoo.fr,oudou_nj@yahoo.fr
}

\begin{abstract}
How to cite this paper: Kowo, M.P., Yimagou, E.K., Andoulo, F.A., Ndam, A.W.N., Jemea, B., Bagnaka, S.A.F.E., Guekam, P.O., Pessidjo, L., Leuwat, E.T., Noah, D.N. and Njoya, O. (2019) Clinical Aspects and Precipitating Factors of Hepatic Encephalopathy Associated with Cirrhosis in a Cameroonian Population. Open Journal of Gastroenterology, 9, 228-238.

https://doi.org/10.4236/ojgas.2019.911026
\end{abstract}

Received: September 17, 2019

Accepted: November 25, 2019

Published: November 28, 2019

Copyright $\odot 2019$ by author(s) and Scientific Research Publishing Inc. This work is licensed under the Creative Commons Attribution International License (CC BY 4.0).

http://creativecommons.org/licenses/by/4.0/

(c) (i) Open Access

\begin{abstract}
Background: Hepatic Encephalopathy (HE), a common complication of cirrhosis, is associated with a pejorative prognosis. This study aims to describe the clinical presentation, precipitating factors and outcome of HE. Methods: This was a cross-sectional multicenter inpatient study in cirrhotic patients admitted for HE in four tertiary hospitals in Yaoundé (Cameroon) from December 2016 to May 2017. The diagnosis of HE was based on West Haven clinical criteria. The diagnosis of cirrhosis was made using clinical and/or biological, endoscopic and/or ultrasonography signs. Results: A total of 53 patients with $\mathrm{HE}$ (mean age: $49.9 \pm 18.9$ years, 35 Males) were included. The frequency of hospital admission for HE was $4.9 \%$. HE grade III was the most common (37.7\%), followed by grades I and II $(26.4 \%$ and $26.4 \%$, respectively). Grade IV was present in $9.4 \%$ of cases. According to the Child-Pugh score, $72.1 \%$ of the patients were at stage C and $27.9 \%$ at stage B. The main precipitating factors found were: constipation (38.5\%), hyponatremia (35.9\%), hepatocellular carcinoma (HCC) (31.7\%), herbal medicine (28.3\%), hypokalemia (25.6\%), gastrointestinal bleeding (22.6\%) and ascitic fluid infection (spontaneous bacterial peritonitis) (13.8\%). In 5.7\% of cases, no factor was identified. Mortality rate during hospitalization was $45.3 \%$ and was significantly associated with stage III (RR $=11.1 ; 95 \%$ CI: 1.9 -
\end{abstract}


$64.5 ; p=0.003)$ and IV (RR $=24 ; 95 \% \mathrm{CI}: 1.6-40.9 ; p=0.01)$ of HE; Child-Pugh C score $(\mathrm{RR}=15.2 ; 95 \% \mathrm{CI}: 1.7-30.1 ; p=0.003)$ and hypokalemia $(\mathrm{RR}=12.2 ; 95 \% \mathrm{CI}: 1.3-19 ; p=0.01)$. Conclusion: $\mathrm{HE}$ is a common complication during cirrhosis with a poor prognosis. In the majority of cases, a precipitating factor could be determined.

\section{Keywords}

Hepatic Encephalopathy, Liver Cirrhosis, West Haven Criteria, Child-Pugh, Cameroon

\section{Introduction}

Hepatic encephalopathy (HE) associated with cirrhosis is a spectrum of neurological or neuropsychiatric manifestations occurring in patients with hepatic cirrhosis [1]. The symptoms of HE can range from simple neurological disorders detectable only by psychometric tests to coma [2]. The prevalence of overt HE at the time of diagnosis of cirrhosis varies from $10 \%$ to $50 \%$ depending on whether cirrhosis is compensated or decompensated and/or the presence of transjugular intrahepatic porto-systemic shunt (TIPS) [2]. The positive diagnosis of HE is based on a bundle of arguments in association with a particular clinical context. There are no specific clinical signs associated with HE. This disorder is classified into 4 stages according to the classification of the West Haven Criteria (WHC), ranging from simple neurological disorders detectable by psychometric tests to coma [3]. The onset of HE must be investigated for a precipitating factor, especially an infectious episode, gastrointestinal bleeding, electrolyte imbalance, constipation, diuretic use [4] [5]. HE in liver cirrhosis is disabling and associated with poor prognosis and high mortality without liver transplantation [6] [7] [8]. In Cameroon, due to the high prevalence of chronic viral hepatitis B and C both in general population and in high-risk group population [9] [10], there is a high incidence of cirrhosis and its complications, including HE. Data on HE during cirrhosis is scarce. We therefore, sought to describe the clinical presentation, precipitating factors and outcome of HE among cirrhotic patients.

\section{Methods}

\subsection{Study Population}

This was a cross-sectional multicenter inpatient study on cirrhotic admitted for $\mathrm{HE}$ in the internal medicine departments of the Yaounde Teaching Hospital, the Yaounde General Hospital, the Yaounde Military Hospital and the gastroenterology department of Yaounde Central Hospital. This study was conducted over a period of 6 months, from December 2016 to May 2017.

All patients with hepatic cirrhosis complicated by $\mathrm{HE}$ and hospitalized in the study sites were included. Patients with chronic liver disease other than cirrhosis, acute liver disease and neurological impairment other than HE associated to 
cirrhosis were excluded.

\subsection{Diagnosis of Cirrhosis and of HE}

The diagnosis of cirrhosis was based on clinical and/or biological (including signs of liver failure and portal hypertension) and/or ultrasonographic signs of cirrhosis (irregular aspect of the liver surface, liver parenchymal texture heterogenous, dilatation of the portal venous system vessels) and/or endoscopic signs of portal hypertension. HE was diagnosed based on clinical signs and they were classified using the WHC classification [3].

\subsection{Data Collection}

Participants in the study were conveniently recruited. Data collected included age, gender, symptoms of HE, signs and symptoms of cirrhosis, signs and symptoms of infection. Laboratory investigations requested included: serum electrolytes, random blood glucose, renal function tests, hepatitis B surface antigen, and hepatitis $\mathrm{C}$ antibodies. Ascitic tap was done and sent for analysis in order to diagnose spontaneous bacterial peritonitis (SBP). The diagnosis of SBP was made in presence of more than 250 of polymorphonuclear cells per ml. Any identified HE precipitating factor was recorded and during hospitalization, clinical outcome was also recorded.

\subsection{Statistical Analysis}

Data was registered using CsPro 6.3 software and analyzed using SPSS 23.0 software (SPSS Inc., Chicago, IL). Relative risk (RR) and the 95\% confidence interval $(95 \% \mathrm{CI})$ were calculated to assess associations between mortality and stage of HE, severity of cirrhosis and precipitating factors of HE in univariate analysis. A $p$ value of $<0.05$ was considered significant.

\section{Ethical Considerations}

Ethical clearance was obtained from the Institutional Research Ethical Committee of the Faculty of Medicine and Biomedical Sciences of the University of Yaoundé I. The administrative authorizations were received from directors of the various hospitals involved in the study and written consent were obtained from all patients included or from their guardians.

\section{Results}

\section{Characteristics of the study population}

During the study period, 53 (4.9\%) patients with cirrhosis associated HE were enrolled out of 1081 hospitalized patients. The mean age was $49.9 \pm 18.9$ years (minimum: 17 and maximum: 85 years). The sex ratio was 2.3 .

\section{Etiologies of cirrhosis}

The most frequent cause of cirrhosis was chronic hepatitis $\mathrm{B}$ virus alone (60\%), followed by chronic hepatitis C virus alone (22.6\%), hepatitis B virus as- 
sociated to hepatitis D virus (7.5\%) and alcohol consumption alone (3.8\%). In $5.7 \%$ of cases the etiology of cirrhosis was unknown. The characteristics of patients are summarized in Table 1.

Description of the different clinical aspects of $\mathrm{HE}$

According to the WHC, stage III of HE was the most represented (37.7\%), followed by grades I and II, respectively in $26.4 \%$ and $26.4 \%$ of cases. Grade IV

Table 1. Baseline characteristics of the study population.

\begin{tabular}{|c|c|c|}
\hline Variables & Number & Percentage (\%) \\
\hline \multicolumn{3}{|l|}{ Gender } \\
\hline Male & 37 & 69.8 \\
\hline Female & 16 & 30.2 \\
\hline \multicolumn{3}{|l|}{ Age groups } \\
\hline \multicolumn{3}{|l|}{ Mean \pm SD $(49.9 \pm 18.9)$} \\
\hline$<20$ & 1 & 1.9 \\
\hline $20-40$ & 21 & 39.6 \\
\hline $41-60$ & 12 & 22.6 \\
\hline$>60$ & 19 & 35.8 \\
\hline \multicolumn{3}{|l|}{ Comorbidities } \\
\hline Diabetes & 8 & 15.1 \\
\hline HIV & 5 & 10 \\
\hline Hypertension & 8 & 15.1 \\
\hline Alcohol & 11 & 20.8 \\
\hline $\mathrm{HCC}$ & 7 & 13.2 \\
\hline \multicolumn{3}{|l|}{ Etiologies of cirrhosis } \\
\hline $\mathrm{HBV}$ & 32 & 60 \\
\hline $\mathrm{HCV}$ & 12 & 22.6 \\
\hline Alcohol & 2 & 3.8 \\
\hline Not identified & 3 & 5.7 \\
\hline \multicolumn{3}{|l|}{ Child Pugh score } \\
\hline Child B & 12 & 27.9 \\
\hline Child C & 31 & 72.1 \\
\hline \multicolumn{3}{|l|}{ Outcome } \\
\hline Alive & 29 & 54.7 \\
\hline Dead & 24 & 45.3 \\
\hline \multicolumn{3}{|l|}{ Biological parameters (Mean \pm SD) } \\
\hline Bilirubin (mg/l) & \multicolumn{2}{|c|}{$57.2 \pm 80$} \\
\hline Albumin (g/l) & \multicolumn{2}{|c|}{$20.3 \pm 14.4$} \\
\hline $\mathrm{TP}(\%)$ & \multicolumn{2}{|c|}{$46.9 \pm 27.4$} \\
\hline Glycemia (g/l) & \multicolumn{2}{|c|}{$0.8 \pm 0.6$} \\
\hline Creatinemia (mg/l) & \multicolumn{2}{|c|}{$13.6 \pm 16.5$} \\
\hline Natremia $(\mathrm{mEq} / \mathrm{l})$ & \multicolumn{2}{|c|}{$103.5 \pm 59.9$} \\
\hline Kalemia (mEq/l) & \multicolumn{2}{|c|}{$3.02 \pm 1.9$} \\
\hline Duration of hospitalization (days) & \multicolumn{2}{|c|}{$8.7 \pm 6$} \\
\hline
\end{tabular}


was present in $9.4 \%$ of cases. Distribution of the grade of HE is show in Table 2.

Child-Pugh classification could be performed in 43 patients. According to this score, 31 patients $(72.1 \%)$ and 12 patients (27.9\%) were classified Child C and Child B respectively.

\section{Precipitating factors}

The main precipitating factors found were: constipation (37.7\%), herbal medicine (28.3\%), hyponatremia (26.4\%), HCC (24.5\%), gastrointestinal bleeding (22.6\%), hypokalemia (15\%), and ascitic fluid infection (7.5\%). No factor was identified in $5.7 \%$ of participants. The precipitating factors are detailed in Table 3.

\section{Outcome:}

The mortality rate during hospitalization was $45.3 \%$. The average admission duration was $8.7 \pm 6$ days. Mortality was significantly associated with stages III [RR $=11.1 ; 95 \% \mathrm{CI}: 1.9-64.5 ; p=0.003]$ and IV [RR $=24 ; 95 \% \mathrm{CI}: 1.6-40.9 ; p$ $=0.01]$ of $\mathrm{HE}$, Child $\mathrm{C}$ score of cirrhosis $[\mathrm{RR}=15.2 ; 95 \% \mathrm{CI}: 1.7-30.1 ; p=$ 0.003 ] and Hypokaliemia [RR = 12.2; 95\% CI: 1.3 - 19; $p=0.01]$ (Table 4).

Table 2. Grades of HE according to the WHC classification.

\begin{tabular}{ccc}
\hline Stages & Number & Percentage (\%) \\
\hline Stage I & 14 & 26.4 \\
Stage II & 14 & 26.4 \\
Stage III & 20 & 37.7 \\
Stage IV & 5 & 9.4 \\
Total & 53 & 100 \\
\hline
\end{tabular}

Table 3. The precipitating factors of HE.

\begin{tabular}{|c|c|c|}
\hline Variables & Number & Percentage (\%) \\
\hline SBP & 4 & 7.5 \\
\hline Gastrointestinal bleeding & 12 & 22.6 \\
\hline Constipation & 20 & 37.7 \\
\hline Hypokaliemia & 8 & 15 \\
\hline Hyponatremia & 14 & 26.4 \\
\hline Herbal medicine & 15 & 28.3 \\
\hline Diuretics overdose & 6 & 11.3 \\
\hline Paracentesis & 2 & 3,8 \\
\hline Diarrhoea & 8 & 15 \\
\hline $\mathrm{HCC}$ & 13 & 24.5 \\
\hline Sedative drugs intake & 1 & 1.9 \\
\hline Unidentified & 3 & 5.7 \\
\hline Cutaneous infection & 3 & 5.7 \\
\hline Lower respiratory tract infection & 3 & 5.7 \\
\hline Urinary tract infection & 2 & 3.8 \\
\hline Malaria & 1 & 1.9 \\
\hline Vomiting & 1 & 1.9 \\
\hline
\end{tabular}


Table 4. Factors associated to mortality of HE.

\begin{tabular}{|c|c|c|c|c|}
\hline Factors & Mortality n (\%) & $\mathbf{R R}$ & IC à $95 \%$ & $P$ \\
\hline \multicolumn{5}{|l|}{ Precipitating factors } \\
\hline Gastrointestinal bleeding & $6(25.0)$ & 1.2 & $0.3-4.6$ & 0.7 \\
\hline Constipation & $8(34.8)$ & 0.7 & $0.2-2.3$ & 0.6 \\
\hline Hyponatremia & $6(35.3)$ & 0.9 & $0.25-3.5$ & 0.9 \\
\hline Hypokaliemia & $7(36.8)$ & 12.2 & $1.3-19$ & 0.01 \\
\hline Diuretics overdose & $4(18.2)$ & 3.0 & $0.4-18.1$ & 0.3 \\
\hline Diarrhoea & $6(25.0)$ & 4.5 & $0.8-24.8$ & 0.1 \\
\hline Paracentesis & $1(4.2)$ & 1.2 & $0.07-20.5$ & 1.0 \\
\hline $\mathrm{HCC}$ & $7(41.2)$ & 2.1 & $0.5-7.9$ & 0.2 \\
\hline Herbal medicine & $5(20.8)$ & 0.5 & $0.1-1.7$ & 0.2 \\
\hline Urinary tract infection & $2(8.3)$ & 1.2 & $0.1-9.4$ & 1.0 \\
\hline Cutaneous infection & $2(8.3)$ & 2.5 & $0.2-29.9$ & 0.5 \\
\hline Lower respiratory tract infection & $3(12.5)$ & 2.3 & $1.7-3.2$ & 0.08 \\
\hline Vomiting & $1(4.2)$ & 2,2 & $1.7-3.1$ & 0.4 \\
\hline \multicolumn{5}{|l|}{ Grades of HE } \\
\hline Grade I & $2(8.3)$ & 1 & - & - \\
\hline Grade II & $5(20.8)$ & 3.3 & $0.5-21.7$ & 0.3 \\
\hline Grade III & $13(54.2)$ & 11.1 & $1.9-64.5$ & 0.003 \\
\hline Garde IV & $4(16.7)$ & 24 & $1.6-40.9$ & 0.01 \\
\hline \multicolumn{5}{|l|}{ Severity of cirrhosis } \\
\hline Child B & $1(2.3$ & 1 & - & - \\
\hline Child C & $18(41.9)$ & 15.2 & $1.7-30.1$ & 0.003 \\
\hline
\end{tabular}

RR: Relative Risk; CI: Confidence Interval; HCC: Hepatocellular Carcinoma.

\section{Discussion}

This study aimed to describe the clinical profile of cirrhosis associated HE, specifically to describe the clinical aspects of HE, determine precipitating factors, and the outcome of cirrhotic related HE in Cameroon.

\subsection{Age and Sex}

The mean age of patients with HE was $49.9 \pm 18.9$ years old. The relatively young age of these patients could be explained by the etiology of cirrhosis. Indeed, the most common cause of cirrhosis in Cameroon is chronic HBV infection, which affects mostly young people [9]. In this area of high endemicity for $\mathrm{HBV}$ infection, high prevalence of the HBV infection has mainly been attributed to HBV transmission occurring predominantly early in the life either through mother to child transmission or horizontal transmission [11] [12].

HE was most common in men (69.8\%). The reason for this finding is not clear but similar results have been reported by some other studies. In the study on 
precipitating factors and treatment outcomes of hepatic encephalopathy in Liver Cirrhosis in Nepal by Poudyal et al., 78\% of patients included were male [5]. In another study by Gad et al. in Egypt $63.3 \%$ of patients with HE in liver cirrhosis were male [13]. This could be as the result of men being more exposed to various risk factors of cirrhosis.

\subsection{Etiologies of Cirrhosis}

Chronic HBV was found to be the main etiology of cirrhosis in our study. HBV infection is frequent in Cameroon which is considered as one of most affected countries in the world with an overall pooled prevalence of $11.2 \%$ [9]. The predominance of hepatitis B as the etiology of cirrhosis could be explained by the high prevalence of HBV in Cameroonian population. Chronic HCV was found in $22.6 \%$ of patients. The high prevalence of HCV reported by several studies in the Cameroonian population [14] [15] might explained this finding.

\subsection{Description of the Different Clinical Aspects of HE}

Grade III of HE was the most represented type in this study. Gad Y et al. in Egypt [13] and Devrajani et al. in Pakistan [16] respectively reported a 54.0\% (128/237) and 80\% (70/87) prevalence of grade III and grade IV HE among admitted patients presenting with signs and symptoms of HE. Most patients in resource limited settings usually present with advanced disease due to late consultations and this might explain the above finding.

\subsection{Precipitating Factors}

Constipation, herbal medicine, hyponatremia, HCC and gastrointestinal bleeding were the most frequent precipitating factors of $\mathrm{HE}$ in our study population. These findings are consistent with those reported by several authors in Pakistan, Egypt and United States of America [4] [13] [17]. In our study, constipation appears to be the most frequent precipitating factor of HE (37.7\%). In fact, gastrointestinal symptoms are common in cirrhotics and constipation has been reported in $8 \%$ of cases [18]. The underlying mechanisms are complex and involve abnormalities in gut motility such as delayed gastric emptying, altered intestinal permeability [19]. Patients with advance cirrhosis are more at risk of developing gut dysfunctions symptoms [19]. In this study $72 \%$ of patients were stage $\mathrm{C}$ of Child-Pugh classification and hence justifying constipation as the most common precipitating factor of $\mathrm{HE}$.

The frequency of electrolytes imbalance was high (hyponatremia: $26.4 \%$; Hypokaliemia: 15\%) and could be partly explained by the effect of diuretics on one hand and secondary hyperaldosteronism on the other hand. Diarrhea found in $15 \%$ of cases could also contribute to electrolytes abnormalities in this study. Spontaneous bacterial peritonitis was found in 4 patients (7.4\%). Increase intestinal permeability, bacterial translocation and decrease in host immunity have been associated with SBP in advanced liver cirrhosis [20]. Therapeutic ascitic tap 
done in dubious conditions in some cases could also explain some cases of ascitic fluid infections. In some patients (5.7\%), no precipitating factor was identified.

\section{Outcome}

The mortality rate associated with $\mathrm{HE}$ was $45.3 \%$ and significantly associated with stages III $(p=0.003)$ and IV $(p=0.01)$ of HE, Child C score of cirrhosis ( $p$ $=0.003)$ and Hypokaliemia $(p=0.01)$. Similar high mortality rates have been reported by studies in Africa. In 2016, Ntagirabiri et al. found a 56\% HE mortality rate among cirrhotic patients [7]. In Nigeria, Onyek were reported a mortality rate of $48 \%$ [21]. This high mortality rate could be explained firstly by the severity of cirrhosis because the majority of patients usually consult in advanced stage of the disease and secondly by the various complications associated with cirrhosis. More so the absence of optimal treatment for certain complications and of liver transplantation in our setting could also explain this high mortality rate. Electrolyte imbalance is common in cirrhotic patients with hyponatremia being most frequently associated with hepatic encephalopathy [22]. In our study, only hypokalemia was found to be significantly associated with mortality among Cameroonian patients with cirrhosis related hepatic encephalopathy. Hypokalemia has been shown to induce hepatic encephalopathy and this is modulated by the kidneys. As less potassium enters the collecting tubules, more hydrogen ions are moved into the cells leading to increase intracellular acidosis. This triggers the conversion of glutamine to ammonia and bicarbonate. The ammonia is selectively either excreted in urine or returned to venous circulation. Ammonia that subsequently enters portal circulation is not metabolized by the cirrhotic patient likely therefore to precipitate hepatic encephalopathy [23].

\section{Limitations of the Study}

One of the limitations of this study is that electroencephalography and brain scan were not done in certain cases to exclude central nervous system involvement. The retrospective nature of the study reduced the number of included files because of their incomplete nature.

\section{Conclusion}

HE is a frequent complication during cirrhosis with a high mortality. The main precipitating factors were constipation, herbal medicine, electrolyte imbalance, gastrointestinal bleeding and HCC.

\section{Data Availability}

All the data used to support the findings of this study are available from the corresponding author upon request.

\section{Authors Contributions}

This work was jointly carried out by all the authors. 
Author MK contributed in collection of data, analysis and editing the article; Author FA contributed in study conception and editing the article. Author EKY wrote the protocol and the first draft of the manuscript. Authors AWNN, BJ, SFEB, POG, ETL, DNN contributed in collection of data and follow-up of the patients. Author ON supervised all the activities and approved the final version to be submitted for publication. All authors read and approved the final manuscript.

\section{Acknowledgements}

None.

\section{Funding}

No funding was available for this study.

\section{Conflicts of Interest}

The authors declare no conflicts of interest regarding the publication of this paper.

\section{References}

[1] Weissenborn, K. (2019) Hepatic Encephalopathy: Definition, Clinical Grading and Diagnostic Principles. Drugs, 79, S5-S9. https://doi.org/10.1007/s40265-018-1018-Z

[2] Vilstrup, H., Amodio, P., Bajaj, J., Cordoba, J., Ferenci, P., Mullen, K.D., et al. (2014) Hepatic Encephalopathy in Chronic Liver Disease: 2014 Practice Guideline by the American Association for the Study of Liver Diseases and the European Association for the Study of the Liver. Hepatology, 60, 715-735.

https://doi.org/10.1002/hep.27210

[3] Ferenci, P., Lockwood, A., Mullen, K., Tarter, R., Weissenborn, K. and Blei, A.T. (2002) Hepatic Encephalopathy-Definition, Nomenclature, Diagnosis, and Quantification: Final Report of the Working Party at the 11th World Congresses of Gastroenterology, Vienna, 1998. Hepatology, 35, 716-721.

https://doi.org/10.1053/jhep.2002.31250

[4] Muntaz, K., Ahmed Syed, U., Abid, S., Baig, N., Hamid, S. and Jafri, W. (2010) Precipitating Factors and The Outcome of Hepatic Encephalopathy in Liver Cirrhosis. Journal of the College of Physicians and Surgeons-Pakistan, 20, 514-518.

[5] Poudyal, N.S., Chaudhary, S., Kc, S., et al. (2019) Precipitating Factors and Treatment Outcomes of Hepatic Encephalopathy in Liver Cirrhosis. Cureus, 11, e4363. https://doi.org/10.7759/cureus.4363

[6] Bustamante, J., Rimola, A., Ventura, P.J., Navasa, M., Cirera, I., Reggiardo, V. and Rodés, J. (1999) Prognostic Significance of Hepatic Encephalopathy in Patients with Cirrhosis. Journal of Hepatology, 30, 890-895.

[7] Ntagirabiri, R., Ntwari, W., Barasukana, P., Munezero, B. and Amani, M. (2016) Encéphalopathie hépatique: Facteurs précipitants, aspects cliniques et évolutifs à Bujumbura. Journal Africain d Hépato-Gastroentérologie, 10, 89-93. https://doi.org/10.1007/s12157-016-0657-5

[8] García-Martínez, R., Simón-Talero, M. and Córdoba, J. (2011) Prognostic Assessment in Patients with Hepatic Encephalopathy. Disease Markers, 31, 171-179. 
https://doi.org/10.1155/2011/832031

[9] Bigna, J.J., Atsama, A., Asangbeh, L., Kenne, M., Noumegni, S., Ngo-Malabo, E., et al. (2017) Seroprevalence of Hepatitis B Virus Infection in Cameroon: A Systematic Review and Meta-Analysis. BMJ Open, 30, e015298.

https://doi.org/10.1136/bmjopen-2016-015298

[10] Kowo, M.P., Andoulo, F.A., Ngek, L.T., Sizimboue, D.T., Ndam, A.N., Ondo, B.E., et al. (2019) Prevalence of Hepatitis C Virus and Associated Risk Factors among Inmates at New Bell Prison, Douala, Cameroon. Open Journal of Epidemiology, 9, 119-128. https://doi.org/10.4236/ojepi.2019.92011

[11] Breakwell, L., Tevi-Benissan, C., Childs, L., Mihigo, R. and Tohme, R. (2017) The Status of Hepatitis B Control in the African Region. The Pan African Medical Journal, 27, 17. https://doi.org/10.11604/pamj.supp.2017.27.3.11981

[12] Dionne-Odom, J., Njei, B. and Tita, A.T.N. (2018) Elimination of Vertical Transmission of Hepatitis B in Africa: A Review of Available Tools and New Opportunities. Clinical Therapeutics, 40, 1255-1267.

https://doi.org/10.1016/j.clinthera.2018.05.016

[13] Gad, Y. (2012) Precipitating Factors of Hepatic Encephalopathy: An Experience at Mansoura Specialized Medical Hospital, Egypt. Annals of Tropical Medicine and Public Health, 5, 330. https://doi.org/10.4103/1755-6783.102044

[14] Bigna, J.J., Amougou, M.A., Asangbeh, S.L., Kenne, A.M. and Nansseu, J.R. (2017) Seroprevalence of Hepatitis C Virus Infection in Cameroon: A Systematic Review and Meta-Analysis. BMJ Open, 7, e015748.

https://doi.org/10.1136/bmjopen-2016-015748

[15] Biwole-Sida, M., Noah, D., Eloumou, A.F., Dang, I., Talla, P., Malongue, C., et al. (2015) Prévalence du portage des anticorps anti VHC dans une population de travailleurs (dépistage en milieu professionnel) au Cameroun. Journal Africain d Hépato-Gastroentérologie, 9, 26-29. https://doi.org/10.1007/s12157-014-0581-5

[16] Devrajani, B.R., Shah, S.Z., Devrajani, T. and Kumar, D. (2009) Precipitating Factors of Hepatic Encephalopathy at a Tertiary Care Hospital Jamshoro, Hyderabad. Journal of Pakistan Medical Association, 59, 683-686.

[17] Pantham, G., Post, A., Venkat, D., Einstadter, D. and Mullen, K.D. (2017) A New Look at Precipitants of Overt Hepatic Encephalopathy in Cirrhosis. Digestive Diseases and Sciences, 62, 2166-2173. https://doi.org/10.1007/s10620-017-4630-y

[18] Fritz, E. and Hammer, J. (2009) Gastrointestinal Symptoms in Patients with Liver Cirrhosis Are Linked to Impaired Quality of Life and Psychological Distress. European Journal of Gastroenterology \& Hepatology, 21, 370-375. https://doi.org/10.1097/MEG.0b013e328318ed19

[19] Kalaitzakis, E. (2014) Gastrointestinal Dysfunction in Liver Cirrhosis. World Journal of Gastroenterology, 20, 14686-14695. https://doi.org/10.3748/wjg.v20.i40.14686

[20] Rostkowska, K.A., Szymanek-Pasternak, A. and Simon, K.A. (2018) Spontaneous Bacterial Peritonitis-Therapeutic Challenges in the Era of Increasing Drug Resistance of Bacteria. Clinical and Experimental Hepatology, 4, 224-231. https://doi.org/10.5114/ceh.2018.80123

[21] Onyekwere, C.A., Ogbera, A.O. and Hameed, L. (2011) Chronic Liver Disease and Hepatic Encephalopathy: Clinical Profile and Outcomes. Nigerian Journal of Clinical Practice, 14, 181-185. https://doi.org/10.4103/1119-3077.84011

[22] Guevara, M., Baccaro, M.E., Torre, A., Gómez-Ansón, B., Ríos, J., Torres, F., et al. (2009) Hyponatremia Is a Risk Factor of Hepatic Encephalopathy in Patients with Cirrhosis: A Prospective Study with Time-Dependent Analysis. The American 
Journal of Gastroenterology, 104, 1382-1389.

[23] Frederick, R.T. (2011) Current Concepts in the Pathophysiology and Management of Hepatic Encephalopathy. Gastroenterology \& Hepatology, 7, 222-233. 